\title{
Enhanced arsenic leaching due to iron and arsenic phase transformations during ceramic water filter production
}

\author{
MichAEL V. SCHAEFER ${ }^{1}$, NINH LE ${ }^{1}$, MACON \\ ABERNATHY ${ }^{2}$, DOMINIQUE NGUYEN ${ }^{3}$, THIDA CORNELL ${ }^{3}$, \\ SAMANTHA C. YING ${ }^{3}$ \\ ${ }^{1}$ Pacific Basin Research Center, Soka University of America, \\ Aliso Viejo, CA 92656; mschaefer@soka.edu \\ ${ }^{2}$ Environmental Toxicology, University of California, \\ Riverside, CA 92521 \\ ${ }^{3}$ Environmental Sciences, University of California, Riverside, \\ CA 92521 \\ Ceramic water filters (CWF) are produced \\ globally using local clay sources and effectively \\ remove bacterial pathogens during point-of-use \\ (POU) water treatment. Ceramic firing at 800 - \\ $900{ }^{\circ} \mathrm{C}$ causes mineralogical changes to arsenic \\ (As) and iron (Fe) that increase As leaching from \\ CWF material compared to source clay. We \\ present whole-filter leaching and wet chemical \\ extraction data combined with X-ray diffraction \\ and X-ray absorption spectroscopy to show that \\ firing converts As from primarily associated with \\ Fe-oxides to $\sim 30 \%$ As in a phase similar to \\ arsenate evaporite minerals. The higher \\ solubility of evaporite As phases combined with \\ increased As-Fe bond distance and $\mathrm{Fe}$ \\ incorporation into the ceramic matrix are each \\ consistent with the observed increase in As \\ leaching. Improved understanding of molecular- \\ scale processes governing increased As leaching \\ from CWFs provides a basis for assessing arsenic \\ leaching potential prior to CWF factory capital \\ investment as well as engineered solutions (e.g. \\ modified firing temperature, material \\ amendments, enhanced leaching prior to \\ distribution) to mitigate As exposure from CWFs. \\ Enhanced As leaching using hot water provides an \\ option to mitigate As exposure from CWFs.
}

